\title{
Fault Analysis of Electric Power System using PLC and Wireless Communication System
}

\author{
Uma Soni, Uma Kumari
}

\begin{abstract}
In present scenario electricity theft is the major hurdle in front of government. This paper comprises of functions and architecture of the smart metering and monitoring network system which works on real time data communication and have its own network. Our main motive is to design and develop such a wireless metering system which will prevent power theft and provide us a reliable and accurate metering monitoring system by using modern technology. The design comprises of wireless power metering and monitoring network which will work on principle of real time data communication(which is not available in existing wireless GSM metering system) and will use its own reliable network with the help of Programmable Logic Controller. Programmable Logic Controller, smart meters, wireless communication modules and profinet cable are the key components of the system. To provide a better and easy human interface with the smart meter we are using simplify S CADA and programming which is very user affable.
\end{abstract}

Keywords:-Wireless NCS , controllers, PLC, SCADA, GSM metering system and smart meter.

\section{INTRODUCTION}

In existing wireless metering system (GSM based) there is no provision of live (real time) metering data monitoring. It can only provide the metering details when request is sent to any node. After receiving request, that particular node sends data in the form of packet. The packet contains the metering data for any specific period of time, not in form of continuous waveform which is the major drawback of GSM wireless meters. These wireless meters(GSM based) are not having their own network, but they are using the mobile networks which is not reliable. Moreover the speed of the network is not up to the mark. In GSM based wireless meters we have only few specific parameters. So to overcome said drawbacks we are developing one metering system which fulfills all these requirements. For that we are using PLC, smart meter, wireless communication modules, profinet cable, and programming of PLC for the communication with smart meter, and SCADA representation of the metering values of smart meter.

\section{A. About PLC}

PLC is a programmable logic controller that contains hardware and software capable of being programmed to perform control functions. A PLC is a controller which performs task on the basis of customize instructions (called program). Normally used for industrial control system. PLC process the inputs on the basis of following steps.

Revised Manuscript Received on April 27, 2020.

Uma Soni*, Research Scholar,Mody University of Science and Technology, Laxmangarh11umasoni@gmail.co m

Dr Uma Kumari, Assistant Professor, Mody University of Science and Technology, Laxmangarh umakumari.cet@modyuniversity.ac.in

(c) The Authors. Published by Blue Eyes Intelligence Engineering and Sciences Publication (BEIESP). This is an open access article under the CC BY-NC-ND license (http://creativecommons.org/licenses/by-nc-nd/4.0/)
- Reading inputs.

- Executing the program.

- Processing communication request.

- $\quad$ Executing CPU diagnosis.

- Writing outputs.

PLC program are typically written in special language on a personnel computer and then downloaded to the PLC. PLC can be programmed using standard based programming languages like FBD (Function Block Diagram), ladder logics, structured text, instruction list and sequential function chart.

\section{B. Hardware Assembly of PLC:-}

PLC is mounted on a rack which is called PLC rack and on the rack first two modules are the power supply modules which give the power supply to the CPU and the remaining modules are mounted on the rack. In two power supply modules one is the redundant.

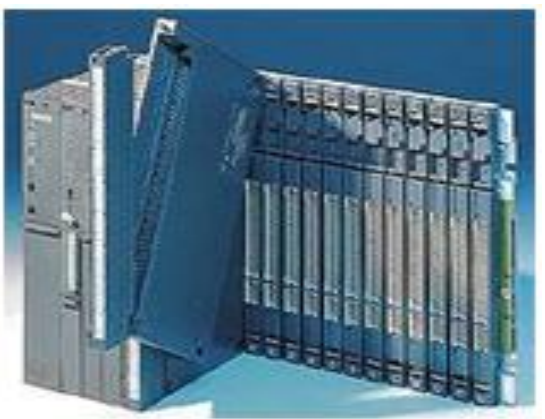

Fig.1:- Rack of PLC

The processor and I/O modules are designed according to the particular application. Several racks can be administered by a single processor and may have thousands of inputs and outputs. It can be designed for multiple arrangements of digital and analog $\mathrm{I} / \mathrm{O}$.

\section{C.User Interface or SCADA:-}

PLCs may have to move with individuals for the aim of configuration and everyday management. A human machine interface (HMI) is employed for this purpose. HMI's are also referred to as man machine interface and graphical user interface. SCADA is a control framework engineering that utilizes PC's, organized information correspondences and graphical user interface for high level state process supervisory administration. The administrator interfaces with SCADA who is monitoring and giving processing command.

II.

\section{LITERATURE SURVEY AND RELATED WORKS}

In India, people are using traditional and simple technique to measure energy such as going door to door to measure the readings .

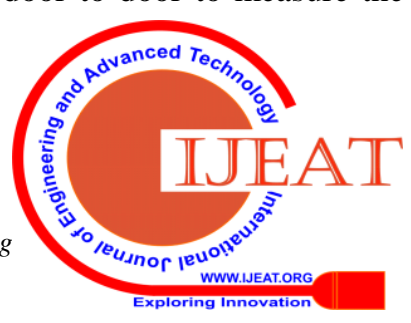


Existing systems such as electronic energy meter(GSM) or an electro-mechanical meter areused to measure energy that are capable of recording $\mathrm{kWh}$ units only.A meter reading company process the recorded data and link each recorded power usage to account holders and generate bills .Based on GPRS, GSM and Bluetooth many energy metering systems have been proposed explained in [1], [2], [3], [4], [5], [6] and [7].To transfer long distance data, a design of Electric Energy Meter based upon GPRS is proposed in [1]. For instant billing, GSM Energy meter is introduced in [8] and [2],but the accuracy and performance degrades due to problem of missing SMS. For multiple accesses GSM wireless meters arrived, which are using advanced Visual studio .net frame work for managing data efficiently even on loss of SMS. But in these meters there are drawbacks such as, they cannot providelive metering data monitoring. Also they are using the GSM network which is not reliable and also they does not have much parameters to display. In these meters data reading is not on real time basis so it is not possible to track power theftimmediately.Our proposed data monitoring system, will provide live status and live data of the meters to track the power theft. It also provide lots of parameters . This metering system will definitely help to reduce power theft, and develop reliable power metering and monitoring system.

\section{WIRELESS METERING SYSTEM ARCHITECTURE AND FUNCTION}

The Wireless module offers one-to-one or one-to-many PROFINET interconnect scenarios. It provides the "backbone" communication for various field devices using different networks including the following combination of applications:

- Wireless extension of network Slaves

- Connection to multiple PROFINET wireless remote device networks

- Communication between multiple and separate networks.

Wireless networks are being increasingly proposed as a basis for NCS implementation. Below is an example of a wireless communication network.

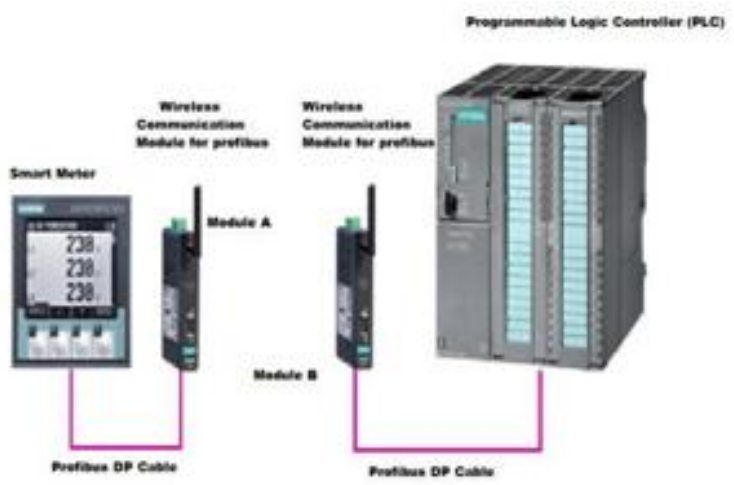

Fig.2: Wireless communication system between Smart meter and PLC.

- In above setup a smart meter is connected to the wireless module A via a profibus DP cable.

- In module A, the node address for the smart meter \& the data mapping shall be done. Data mapping shall be done with respect to the data available from smart meter and shall be different depending upon the manufacture.

- $\quad$ Programmable logic controller (PLC) is connected to module $\mathrm{B}$ via profinet cable.

- In module B, the data mapping shall be done as per module A \& communication through both the modules shall be established via wireless.

- In PLC, the General Station Description (GSD) file of module $B$ shall be installed. The GSD are made by corresponding manufactures for profinet communication.

- In module $\mathrm{B}$, a unique node address shall be set to communicate with the PLC. Once the GSD is installed in PLC, node address is assigned \& data mapping is performed. We are able to communicate the module B with the PLC resulting in fetching real time data from the smart meter.

\section{A. Communication with Smart Meter:-}

- For communication with a smart meter we need to define hardware configuration in PLC program and we have one PLC card (with hardware details) and there is a DP port, and a device connected with profibus DP in the field.

- After defining communication medium, next is to define devices connected with profibus DP.For that there is a need to install the catalogue of the smart meter (because we need to define to PLC that which model of meter we are going to connect), this catalogue file is called GSD file.

- After installation of the GSD file, observe the meter model no. and details on right side.

- Out of all the parameters, select the parameters according to need (just drag and drop from the parameter window). Also define the memory address for that particular parameter, for e.g. if there is a R-phase current we want to show on SCADA screen then we need to select that phase current as parameter and then assign address according to need.

- $\quad$ After defining abovesettings, download all these in the PLC(CPU).

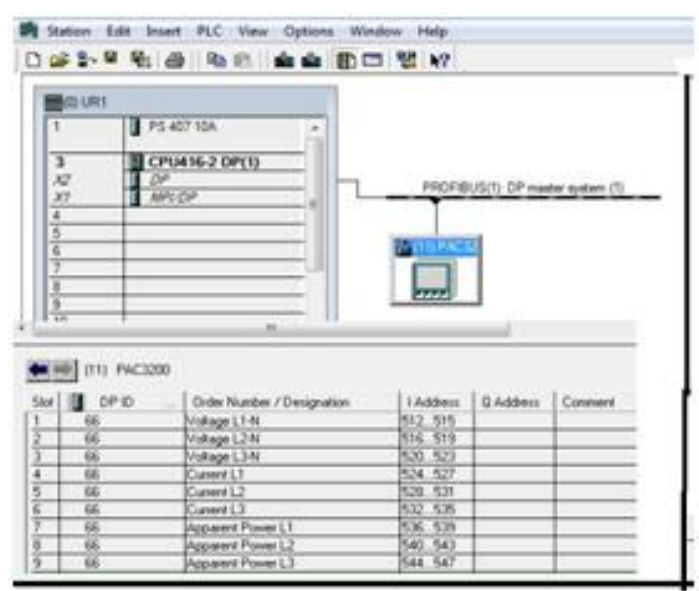

Fig.3:- Communication of PLC with smart meter.

Blue Eyes Intelligence Engineering

\& Sciences Publication

(C) Copyright: All rights reserved.

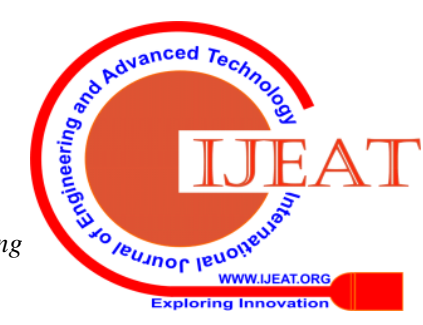


- In PLC program there is a VAT table to check the real time value of any parameter, in which if we type memory address of any parameter which we defined during hardware configuration and communication of smart meter than the real time values of that particular parameter can be observed. Suppose L1 phase current value we want to see in VAT table then just in the address we need to write IW 524(memory address of L1 phase current) where IW is Input Word.

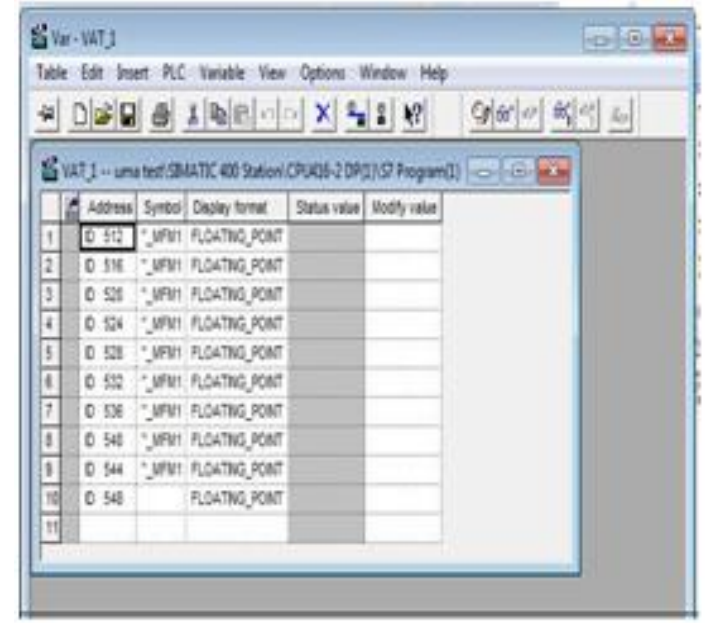

Fig.4: VAT table of real time values.

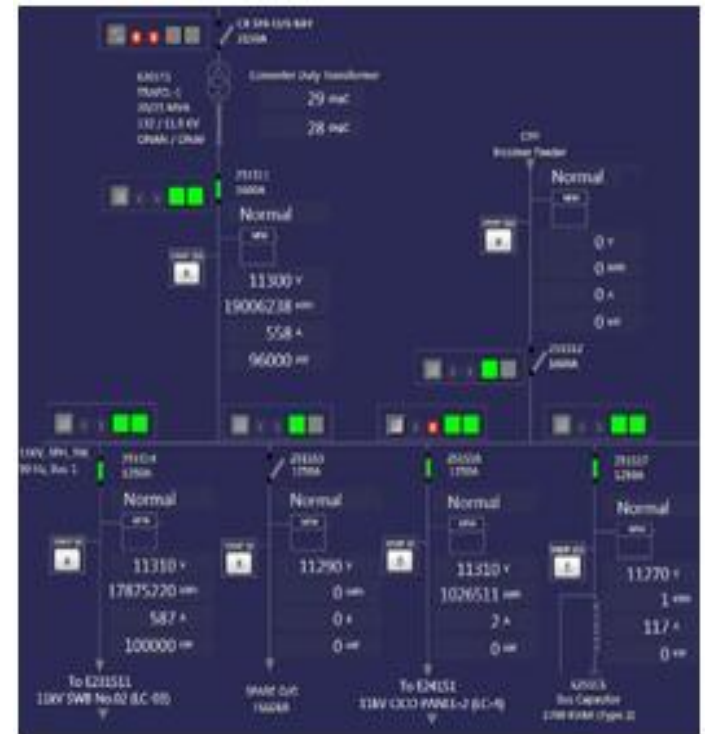

Fig.5:- SCADA representation of smart meter values.

- $\quad$ SCADA is used to know the values from meter. At any point of time data can be obtained. This helps in analyzing fault in power lines immediately because this project carry real time cyclic data.

\section{IV. \\ PLC PROGRAMMING FOR SMART METER DATA}

1. Following Fig. 6 depicts voltage readings from meter.In program simulation block we are just entering the mapping address of the voltage between L1-L2 phase and at the output of the block we are getting voltage values (405.655V). Same mapping address we are entering for L2-L3, L3-L1 phase voltage. And the respective values obtained are $406.285 \mathrm{~V}$ and $406.534 \mathrm{~V}$.

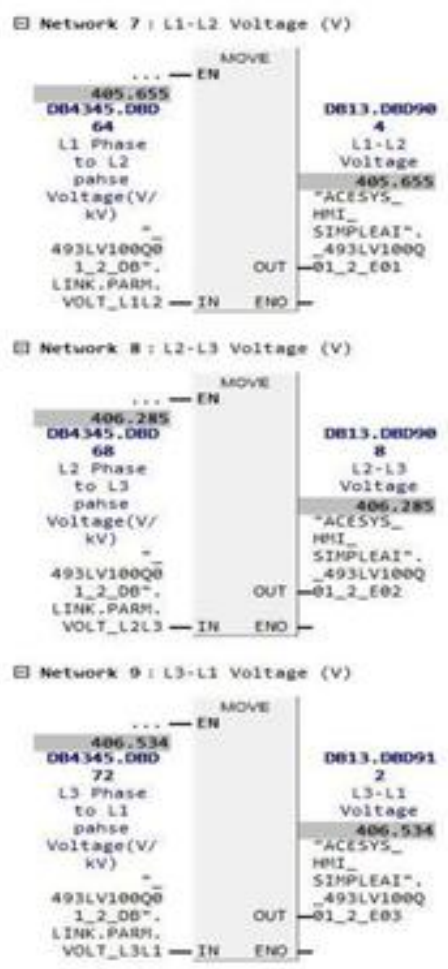

Fig.6: Voltage value for L1, L2, L3 phase

2. In the same manner we obtained readings for phase current, in which just by entering the mapping address for L1 line current that is DB4345.DBD80, the output we are getting on the $\mathrm{L} 1$ current values is 2.89682A. Same can be repeated for L2, L3 line current.

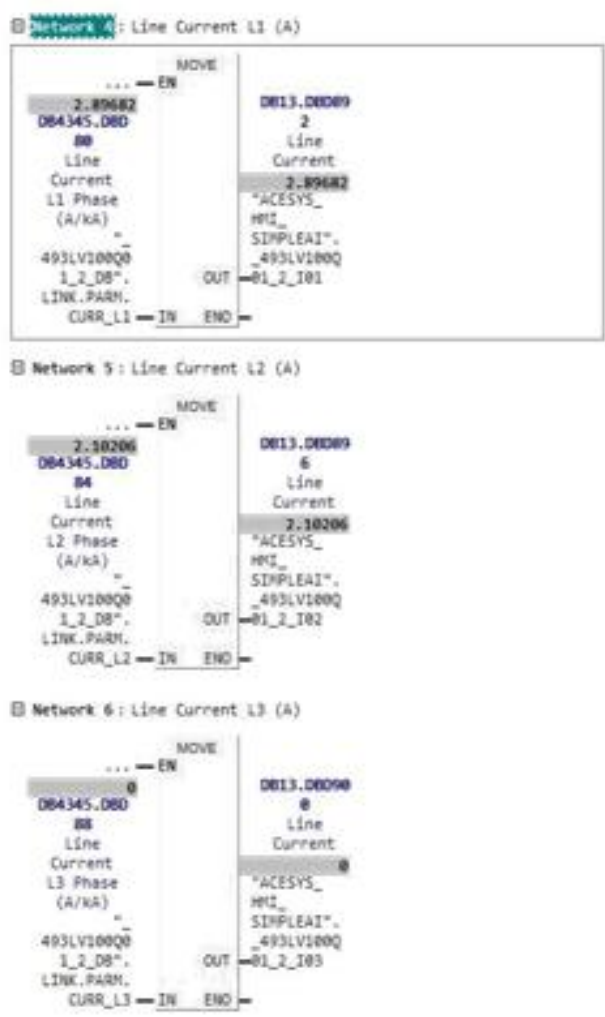

Fig.7: Current values for L1, L2, and L3 phase

Published By:

Blue Eyes Intelligence Engineering \& Sciences Publication (C) Copyright: All rights reserved.

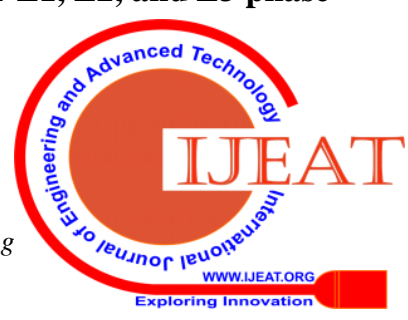


3. Same simulation values for power, frequency and power factor can be generated by using the mapping address es in simulation PLC programming blocks.

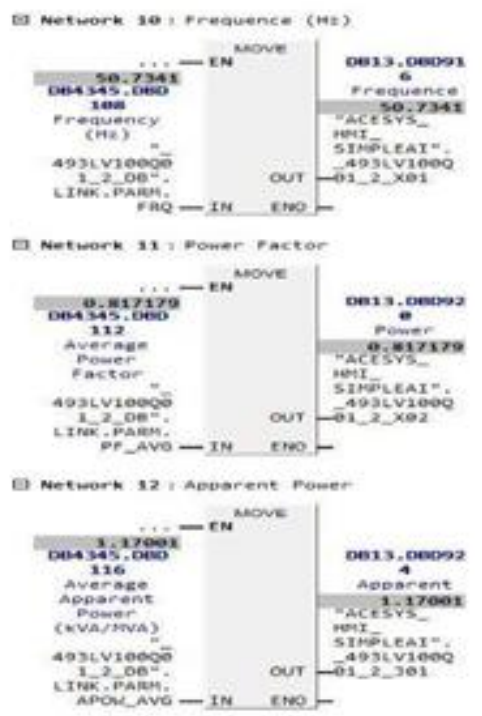

Fig.8: Frequency and power values.

4. SCADA representation for the same values are in Fig. 9 , for these values we need to create the points on the SCADA screen for the V, I, KW and PF.

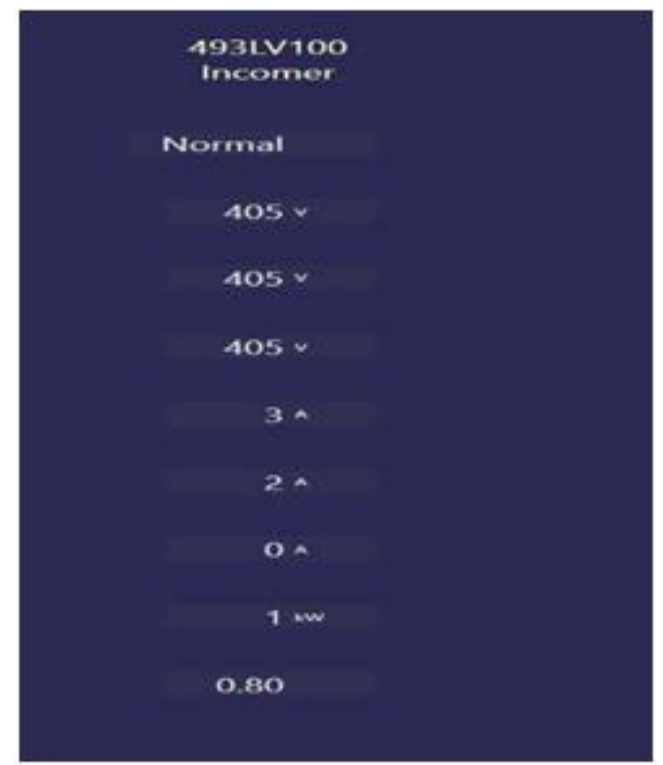

Fig.9:SCADA representation of real time values of voltage current and power.

\section{RESULTS AND ANNALYSIS}

1. The proposed power metering and monitoring system is based on the real time data communication. We can see the live data or real time data of the meter as well as the live or real time status of the meter(which is not available in other meters). If anybody is doing anything with meter then immediately it can be caught because all the meter parameters are live. Even if any interruption is created then also it can easily detected.Below is the graphical representation of apparent power values with respect to time (in minutes and seconds).This graphical format is directly provided by meter in SCADA.Same graphical representation is mentioned for current (in AMPs.) with respect to time (in seconds and minutes) and for voltage (in Volts) with respect to time.

2. These meters are having their own network so that the speed of data(meter parameters) transfer from meter to PC will be fast as compared to other meters( this facility is not available in other meters).

In these meters we have parameters on SCADA screen so it is very easy to monitor all the meter's parameters.

\section{A. Wi-Fi smart meter result:-}

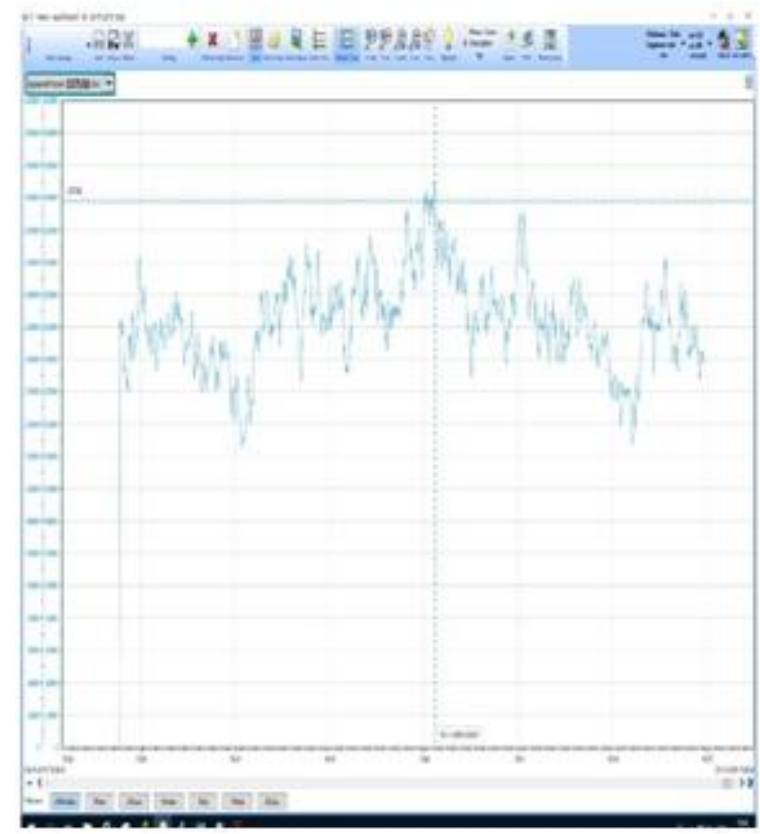

Fig.:10: Apparent power values V/S time

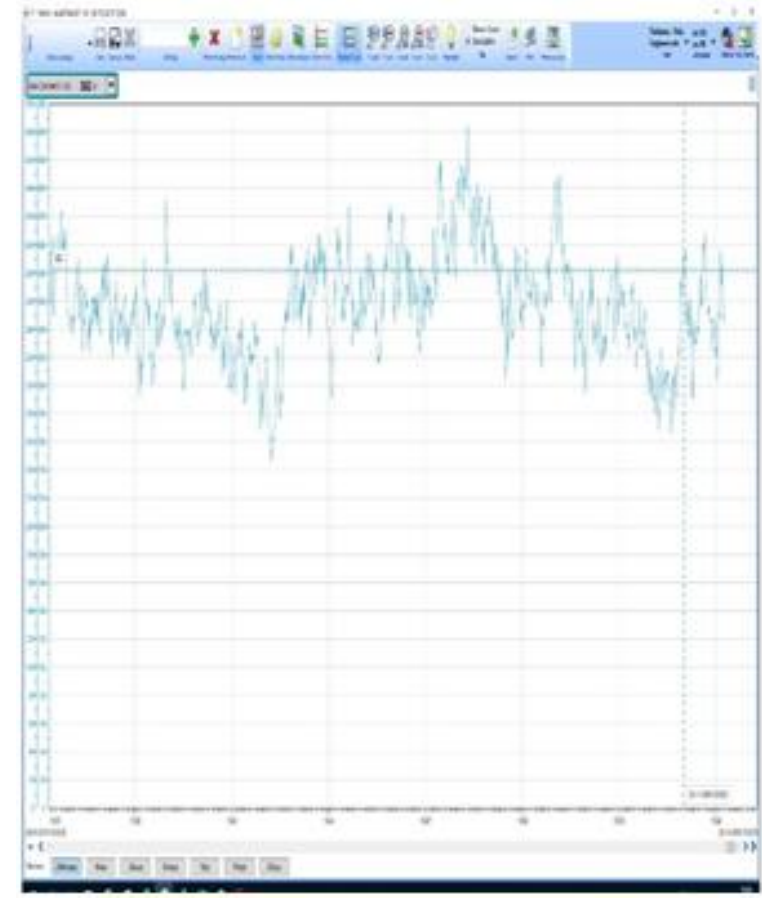

Fig.11:-Current V/S time

Published By:

Blue Eyes Intelligence Engineering

\& Sciences Publication

(C) Copyright: All rights reserved. 


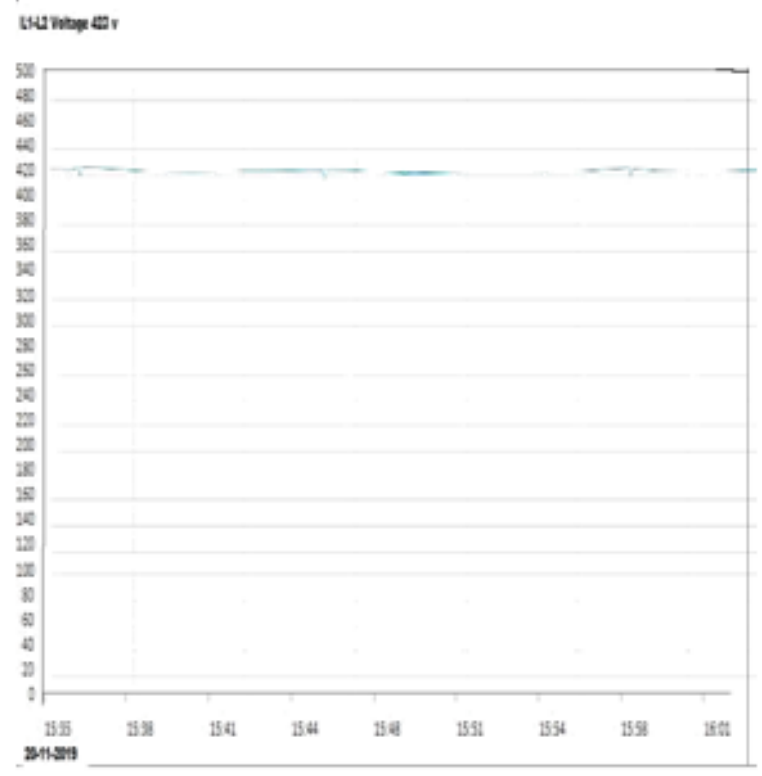

Fig.12: Voltage V/S T ime

\section{B. GSM Meter Result}

In wireless GSM meters there is no provision of live parameter monitoring, in which request is provided to a particular meter through SCADA screen and in return the meter provide a file which contain very few parameters[9][10]. This means we cannot select the parameters as well as the readings on any particular time. In this process we assign a particular time, and that meter provide us reading of that particular time, for example: if we need Kwh reading on 12AM then we need to specify in the SCADA that particular time and name of parameters that we want to retrieve. The meter will record and provide us that particular data. But we don't have the provision to check the parameter on any time. Fig. 13 and Fig. 14 are the screen shoot of the details generated by wireless GSM meter.

Fig 13 and 14 have parameters which were provided by wireless GSM meter, in which meter has generated active, reactive and apparent power reading at $12 \mathrm{AM}$ and date wise.

There is 1-8 parameter readings provided and parameter description is given on the top of the screen shoot.

So the main drawbacks of these meters isthat we don't have choices to get any of parameters readings at any second of time. Also the network of these meters are not reliable because they use SIM based GSM networks which can fail at any time. There can be a case that network gets slow due to overloading on network. These problems are removed in proposed network.

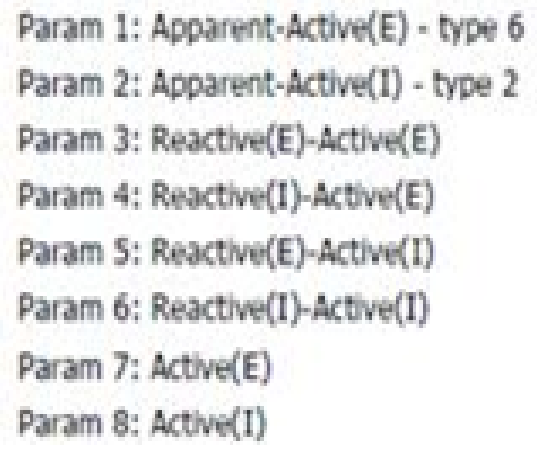

Fig.13:- GSM meter readings calculation.

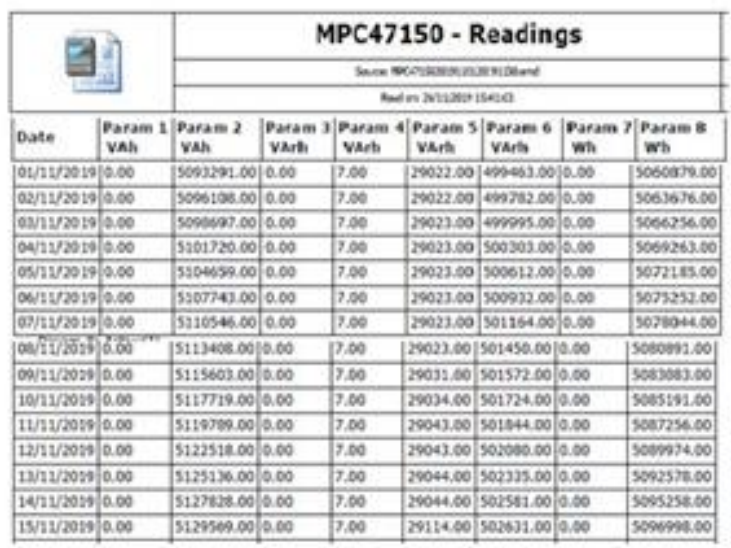

Fig. 14:- GSM meter power readings.

\section{CONCLUSION}

Different types of electronic meters have been developed with different advantages and are still being developed but the proposal of our smart meters (with wireless arrangement)provides different advanceadvantages. The developed system is highly effective in the sense it is able to eliminate the drawback of wireless GSM meters and other wireless meters. The main advantage of this system is the real time data communication with its own network which is not possible in the other networks (wireless meters available in the market like GSM wireless meters).Since it is working on the principle of real time

data communication so every meter can be tracked online and also parameters can be obtained online.Power consumption of this wireless metering system is minimumandit ensure precisetransmission of readings to a remote station. By using real time values of energy meter or smart meter we can generate bills of energy demand patterns and diagnose fault more efficiently and manage or crack fault better and efficiently than others existing. Since this metering system is having its own network so the reliability and accuracy of the system is higher than the other metering systems.

The system also poses safety points since human interaction has been minimized. For future reference the generated bills are available online at any point of time and hard copies can be sent to the consumer by postal mail. More efficient is to send soft copy to the consumers e-mail address after registration of e-mail address.

\section{REFERENCES}

1. YujunBao and Xiaoyan Jiang, "Design of electric Energy Meter for long-distance data information transfers which based upon GPRS", ISA 2009.International Workshop on Intelligent Systems and Applications, 2009.

2. Vivek Kumar Sehgal,Nitesh Panda, NipunRaiHanda, "Electronic Energy Meter with instant billing",UKSim Fourth European Modelling Symposium on Computer Modelling and Simulation. [4] Bharath P, Ananth N,Vijetha S, Jyothi Prakash K. V. ,"Wireless automated digital Energy Meter", ICSET 2008.

3. P.K. Lee and L.L. Lai, Fieee, "A practical approach to wireless GPRS on-line power quality monitoring system”, Power Engineering Society General Meeting,2007.

4. SubhashisMaitra, "Embedded Energy Meter- A new concept to measure the energy consumed by a consumer and to pay the bill", Power System T echnology and IEEE Power India Conference, 2008.

Published By:

Blue Eyes Intelligence Engineering

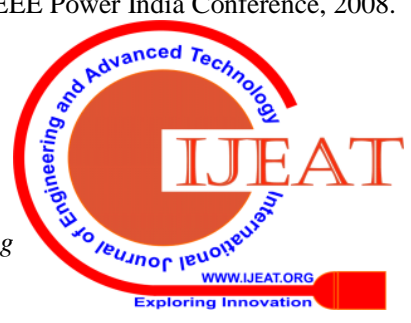

\& Sciences Publication

(C) Copyright: All rights reserved. 
5. T El-Djazairy, B J Beggs and I F Stewart, "Investigation of the use of the Global System for Mobile Communications (GSM) network for metering and load management telemetry", Electricity Distribution. Part 1: Contributions. CIRED. 14th International Conference and Exhibition on (IEE Conf. Publ. No. 438).

6. Li Kaicheng, Liu Jianfeng, YueCongyuan, Zhang Ming."Remote power management and meter-reading system based on ARM microprocessor", PrecisionElectromagnetic Measurements Digest, 2008. CPEM 2008. Conference on Digital Object Identifier.

7. Ashna. K,Sudhish N George, "GSM Based Automatic Energy Meter Reading System with Instant Billing",978- 1-4673-5090-7/13@2013 IEEE, pp 65-71.

8. H.G.RodneyTan,C.H. Lee,V.H.Mok,"Automatic power meter reading system using GSM network", $\mathrm{T}$ he $8^{\text {th }}$ Conference International Power Engineering (IPEC 2007).

9. S.Arun,Dr.Sidappa Naidu, "Design and Implementation of Automatic Meter Reading System Using GSM,ZIGBEE through GPRS", ISSN 2277 128X ,International Journal of Advanced Research in Computer Science and Software Engineering,Volume 2, Issue 5, pp. 321-325,May 2012.

10. Prof. M. S. Sujatha and Dr. M Vijay Kumar "On -line Monitoring an Analysis of Fault in T ransmission and Distribution Line Using GSM T echnique" $30^{\text {th }}$ November 2011 IEEE. Vol. 33 No.2.

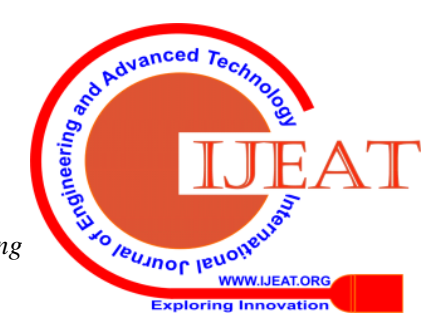

